\title{
Prediction of Symptoms of Cavitation ${ }^{1}$
}

\author{
Robert B. Jacobs
}

(April 26, 1961)

\begin{abstract}
An analysis which indicates some of the basic problems in cavitation and which may permit the prediction of cavitation characteristics of hydraulic equipment is presented. Some experimental results are discussed and are compared with the results of the analysis.

It is concluded that the analysis may be applicable to the prediction of symptoms of cavitation (changes in performance characteristics due to the presence of cavitation), but that more information related to metastability, nucleation, and vapor-phase dynamics is required.
\end{abstract}

\section{Introduction}

The prediction of cavitation in hydraulic equipment has been of interest to designers, manufacturers, and users for many years. Essentially all of the work in this area consists of testing which provides information that is applicable only to the fluid and equipment used in the tests. Investigations concerned with basic problems of cavitation have not been pursued as vigorously. The purpose of this paper is twofold: (1) To present an analysis which indicates some of the basic problems in cavitation and which may permit the prediction of cavitation characteristics, and (2) To discuss some experimental results which have been obtained and compare these with the results of the analysis.

Cavitation can occur in any type of hydraulic equipment in which the local static pressure can drop below the local vapor pressure, with a consequent formation of a vapor phase. It can occur in simple equipment such as a pipe and in the most complicated rotating machinery such as a pump or turbine.

Cavitation may be said to occur whenever a cavity forms in a liquid; in hydraulic equipment this cavity is usually filled with vapor from the surrounding liquid, or with a mixture of this vapor and gaseous impurities. Cavitation is frequently associated with certain symptoms. To some, cavitation exists as soon as one, or a very few, small vapor bubbles appear in the system; to others, cavitation exists if damage results; to a third group, cavitation exists when audible sounds are created. Clearly, the symptoms of interest must be specified if the concept of the "existence of cavitation" is to be significant.

This study will be concerned with cavitation that is sufficiently developed to cause a detectable alteration in the performance of equipment. Usually, an appreciable amount of vapor will form and there may be damage or noise. The symptoms of cavitation to be predicted are therefore changes in performance characteristics such as the head-capacity characteristics of a pump, and the calibration curve of a flow meter.

Examples of the empirical work concerning cavitation include that of Lindros [1], ${ }^{2}$ Rankin [2],

1 Contribution from the Cryogenic Engineering Laboratory, National Bureau ofStandards, Boulder, Colo.

2 Figures in brackets indicate the literature references at the end of this paper.
Weltmer [3], Hartman [4], and Wood [5]. In these investigations the application of the results is limited because an insight into the basic phenomena is not a primary objective of the experiments. A limited number of studies (e.g., Stahl and Stepanoff [6]) have attempted to gain more widely applicable information through more detailed considerations of the phenomena in systems where appreciable cavitation occurs. Here the influence of fluid properties on cavitation characteristics will be emphasized. (Fluids of significantly different properties are considered as different fluids, even though they have the same chemical composition.)

\section{Analysis}

Consider the device in figure 1 , a piece of volumetric equipment such as a pump, venturi, or valve. Regardless of the liquid, the volume flow rates will be the same at the same non-cavitating operating point. Viscous and compressibility effects are assumed negligible (experiments by Richards [7], Purcell [8], and Martin [9] show that this assumption is acceptable). Under the same assumptions it follows (and experience confirms) that the static pressure gradients within the device (expressed in height of liquid) are essentially independent of the liquid. For example, in a non-cavitating pump operating at

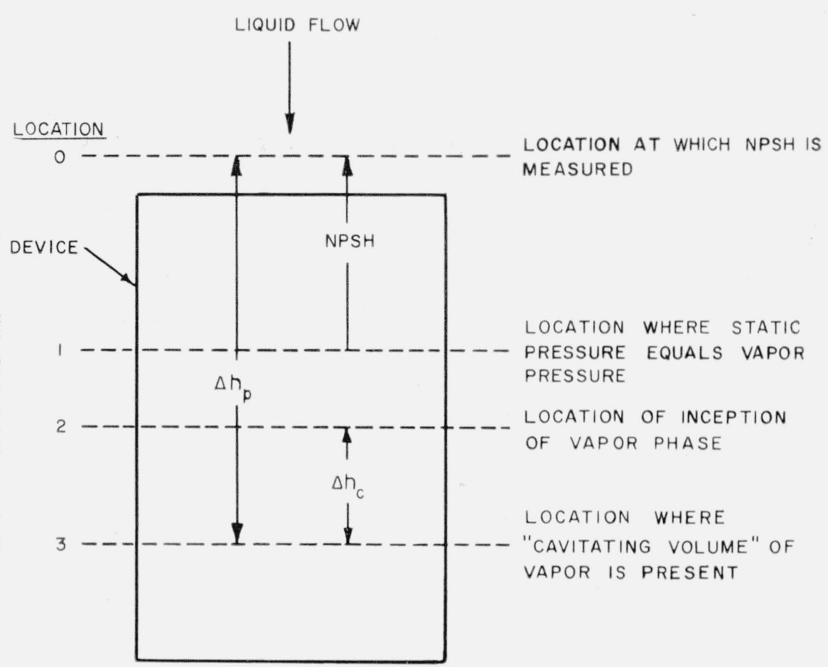

FIGURE 1. Pertinent locations and head drops in a cavitating device: 
a given speed and capacity, the static head-drop from the inlet to any point within the pump is independent of the liquid.

Consider the pressure level in the device to be lowered until a change in performance, due to cavitation, is incipient. This does not mean however that the vapor phase may not be well developed. Immediately before the symptoms of cavitation become evident the pressure and velocity distributions in the device (to location 2 in fig. 1 where the vapor phase is starting to form) do not depend upon the fluid. Thus, the differences in cavitation characteristics of different fluids, in the same device, are due to the differences in what occurs in those regions of the device that are downstream of the point of vapor inception. (Note that differences in nucleation characteristics of liquids can alter the location of the point of vapor inception for different fluids.) Attention is therefore focused on the differences in behavior of the fluids after the static pressure has dropped to, or perhaps somewhat below, the vapor pressure. The concern here is with what occurs between locations 2 and 3 in the device in figure 1 ; if stable equilibrium exists, locations 1 and 2 coincide.

The work of Stahl and Stepanoff [6] has the same purpose as this analysis, but the basic assumptions and therefore the final results of the two analyses differ. The major difference is that: In this analysis the head depression, below the pressure at which vaporization starts (not necessarily the vapor pressure), required to generate a "cavitating volume" of vapor is calculated, and it is assumed that differences in this head account for the variations in cavitation characteristics of different fluids. Stahl and Stepanoff calculate the vapor-to-liquid-volume ratio formed because of a given head depression, and assume that this ratio is an indication of cavitation characteristics. In addition, this analysis accounts for characteristics of the hydraulic device. Salemann [10] has discussed some aspects of the analysis presented here, as well as that of Stahl and Stepanoff.

\subsection{Nomenclature}

$C=$ defined as $\left[C_{p l}+v_{l}\left(1-T_{\imath} \beta_{l}\right)\left(\frac{d p}{d T}\right)\right]$, temperature coefficient for determining changes in the enthalpy of the liquid during the vaporization process.

$C_{p}=$ isobaric specific heat of liquid.

$h=$ specific enthalpy of fluid in region of cavitation.

$N=$ pump speed.

$p=$ pressure.

$Q=$ pump capacity.

$T=$ temperature.

$u=$ mean fluid velocity in the region of cavitation.

$V=$ volume of vapor per unit volume of mixture in region of cavitation when symptoms of cavitation are incipient.

$v=$ specific volume. $x=$ quality of fluid in region of cavitation.

$x_{c}=$ quality in the region of cavitation when symptoms of cavitation are incipient.

$\Delta h_{c}=$ drop in head, measured in height of liquid, which is necessary to cause incipient symptoms of cavitation.

$\Delta h_{p}=$ head drop experienced by a particle of fluid as it travels from the pump inlet to the region where cavitation is occurring.

$\Delta p_{c}=$ pressure drop, after vaporization begins, necessary to cause sufficient flashing to produce incipient symptoms of cavitation.

$\beta=$ coefficient of expansion, $\frac{1}{v}\left(\frac{\partial v}{\partial T}\right)_{p}$

$\delta=\mathrm{a}$ function of $\phi$ and fluid properties, defined by eq (13).

$\lambda=$ latent heat of vaporization.

$\rho=$ density.

$\phi=$ defined as $V /(1-V)$, and is generally a function of design, operating point, and fluid.

$\chi=\mathrm{a}$ function defined by eqs (7) and (8).

Subscripts: $f$ refers to saturated liquid.

$g$ refers to saturated vapor.

$l$ refers to liquid.

$v$ refers to vapor.

$1,2,3, \ldots n \ldots$ used to identify fluids.

\subsection{Derivation of Equations}

Assuming that steady flow exists, heat transfer and shaft work are negligible during the flashing process, and that effects of force fields are negligible, the energy equation may be written

$$
d h+d\left(\frac{u^{2}}{2}\right)=0
$$

Assume further that $h=h_{l}+x \lambda, \lambda$ is constant, and that temperature is a function of pressure only. The energy equation becomes:

$$
C\left(\frac{d T}{d p}\right) d p+\lambda d x+d\left(\frac{u^{2}}{2}\right)=0 .
$$

The temperature coefficient, $C$, is defined as

$$
\frac{d h_{l}}{d T} \equiv C \equiv\left[C_{p_{l}}+v_{l}\left(1-T_{l} \beta_{l}\right)\left(\frac{d p}{d T}\right)\right] .
$$

The derivative $\left(\frac{d T}{d p}\right)$ is the slope of the vaporpressure curve only if the liguid and vapor are in. stable equilibrium; generally, this is not the case, and the function $T(p)$ will depend upon those properties of the fluid which determine its ability to exist in metastable states. Also $\lambda$ may not be exactly equal to the usual (stable equilibrium) latent heat of vaporization.

Assuming that steady state exists, and that viscous. drag, changes in cross-sectional area, and changes in flow direction can be neglected during the flashing 
process, the momentum equation can be written

$$
d p+d\left(\rho u^{2}\right)=0 .
$$

The limitations introduced by the preceding assumptions may be relaxed in the application of the results of this analysis because the characteristics of different fluids passing through the same device are to be compared; it is anticipated that the fluid properties will be important and that the geometrical effects will tend to cancel out.

Using the previous assumptions, the continuity equation may be written

$$
d(\rho u)=0 .
$$

Assuming that $1 / \rho=\left[(1-x) v_{l}+x v_{v}\right]$ and that $x<<1$ or $v_{l}<<v_{v}$, and combining equations 1,2 , and 3 , we have

$$
d p=\frac{\lambda d x}{\left[v_{l}+x v_{v}-C\left(\frac{d T}{d p}\right)\right]} .
$$

Note that $v_{l}$ and $v_{v}$ are the specific volumes of saturated liquid and vapor only if the fluid is in stable equilibrium. Assume that $v_{l}, v_{v}, C$, and $\left(\frac{d T}{d p}\right)$ are not functions of $x$. The preceding expression can then be integrated. Evaluating the constant of integration from the condition that $\Delta p=0$ when $x=0$, we obtain

$$
\Delta p=\frac{\lambda}{v_{v}} \ln \left\{1+\frac{x v_{v}}{\left[v_{l}-C\left(\frac{d T}{d p}\right)\right]}\right\} .
$$

It is important to note that the pressure at which $\Delta p=0$ is not the local vapor pressure, but depends upon the metastability and nucleation characteristics of the liquid. As these characteristics vary from liquid to liquid, it follows that the initial pressure, and hence the region in the device at which eq (4) is to be applied (i.e., between locations 2 and 3 ) depends upon the fluid. Equation (4) gives the change in pressure $(\Delta p)$ which must occur if a fraction $x$ of pure liquid is to vaporize by flashing.

Recall the basic premise that the symptoms of cavitation will occur when a "cavitating volume" of vapor forms in some region of the device. The location of the region and the volume of vapor depend upon the design of the device, the operating point, and probably upon the fluid; the location can be in the eye of an impeller, in a small localized low pressure region, or across a flow passage. If $x_{c}$ is the quality in the cavitating region, then $x_{c} v_{v}$ is the volume of vapor per unit mass of mixture in the region. Therefore

$$
\Delta p_{c}=\frac{\lambda}{v_{v}} \ln \left\{1+\frac{x_{c} v_{v}}{\left[v_{l}-C\left(\frac{d T}{d p}\right)\right]}\right\},
$$

where $\Delta p_{c}$ is the pressure drop, after vaporization begins, necessary to cause sufficient flashing to produce symptoms of cavitation.

Note that $x_{c} v_{v}$ is the volume of vapor formed per unit mass of mixture. As equal volumes, not equal masses, of fluid flow through the device per unit time, we should be concerned with cavitating volumes of vapor per unit volume of mixture. Because of previous assumptions, we may write $\left(x_{c} v_{v}\right) \approx v_{l}[V /$ $(1-V)]$, where $V$ is the volume of vapor per unit volume of mixture in the cavitating region. (This $V$ is the same as $V^{\prime}$ mentioned by Salemann [10].)

In eq (5), $\Delta p_{c}$ is expressed in pressure units; i.e., force/area. This quantity could be directly compared from fluid to fluid if it were expressed in height of the flowing liquid. Substituting for $\left(x_{c} v_{v}\right)$ and $\Delta p_{c}$ in eq (5), we obtain

$$
\Delta h_{c}=\frac{\lambda v_{l}}{v_{0}} \ln \left\{1+\frac{\frac{V}{(1-V)}}{\left[1-\frac{C}{v_{l}}\left(\frac{d T}{d p}\right)\right]}\right\} .
$$

Equation (6) gives the drop in head $\Delta h_{c}$, measured in height of liquid, which would accompany the formation of a volume, $V$, of vapor per unit volume of mixture in the cavitating region, and which is therefore necessary to initiate symptoms of cavitation.

One is tempted to say that, for a given device and operating point (e.g., for a given speed, $N$, and capacity, $Q$, in a pump) the vapor volume ratio, $V$, may be the same for all fluids. In view of what has been said previously concerning metastability, nucleation, and vapor-phase dynamics, $V$ is probably also a function of the fluid. Defining a function

$$
\phi \text { (operating point, fluid) } \equiv \frac{V}{(1-V)},
$$

we have

$$
\Delta h_{\mathrm{c}}=\frac{\lambda v_{l}}{v_{v}} \ln \left\{1+\frac{\phi}{\left[1-\frac{C}{v_{l}}\left(\frac{d T}{d p}\right)\right]}\right\},
$$

where the function $\phi$ is to be determined either experimentally or by further analysis. The analysis presented by $\mathrm{Wu}[11]$ is an example of a theoretical approach which can predict the vapor volume ratio, $V$. Wu determines the effect of an attached region of vapor upon the lift and drag coefficients of a body in the flow passage. When the volume of this region is great enough to appreciably effect the lift and drag of the body, the performance of the device (e.g., pump) will be affected; this computed volume will then be the "vapor volume" in the cavitating region.

If no information is available regarding metastability, nucleation, and vapor-phase dynamics, the functions $T(p)$ and $C$ cannot be predicted. In addition, if the fluids to be compared do not cavitate similarly (i.e., $\phi$ depends upon the fluid) eq (7) may be written in the form 


$$
\Delta h_{c}=\frac{\lambda v_{l}}{v_{v}} \chi \text { (operating point, fluid), }
$$

where the function $\chi$ must be obtained by cavitation tests on the device at different operating points and with different fluids.

\subsection{Application to Pumps}

In order to indicate how the results obtained in the preceding section can be used, and to indicate some of the unresolved problems, the application of the results to the prediction of symptoms of cavitation in pumps will be discussed.

First it is necessary to relate the head drop, $\Delta h_{c}$, with some measurable quantity which is related to cavitation characteristics. The relations formulated here are primarily for illustrative purposes; their predictions compare poorly with the available experimental data. Possible reasons for this will be indicated as the formulation develops. Because of its wide use in pumping, the net positive suction head (NPSH) (i.e., the difference between the total pressure and the vapor pressure at the pump suction) will be used as the measurable quantity. During the remainder of this discussion, the term (NPSH) will mean the minimum NPSH required to suppress symptoms of cavitation.

One way to set up the required relationship is as follows: Consider the drop in head, $\Delta h_{p}$, experienced by a particle of liquid as it travels from the region where the NPSH is measured to the region where the cavitation is occurring. (See fig. 1.) For a given pump and given operating point, $\Delta h_{p}$ is assumed to be about the same for all fluids if the pump is not cavitating. (It has been implied that the location of the cavitation does not depend upon the fluid, which is not generally true.) Assume that

$$
\Delta h_{p}=(\mathrm{NPSH})-\Delta h_{\bullet}
$$

(Both $\Delta h_{p}$ and (NPSH) are positive, while $\Delta h_{c}$ is negative.) Noting that NPSH represents the head drop from the inlet to the vapor pressure, and that $\Delta h_{c}$ is reckoned, not from the vapor pressure, but from the pressure at which vaporization begins (refer to fig. 1), it is apparent that eq (9) is not exact. In addition, the alteration of the flow pattern within the pump due to the presence of the cavitating fluid is ignored. If, in spite of these limitations, $\Delta h_{p}$ is assumed independent of the fluid being pumped, it follows that

$$
\begin{aligned}
(\mathrm{NPSH})_{1}-\left(\Delta h_{c}\right)_{1} & =(\mathrm{NPSH})_{2}-\left(\Delta h_{c}\right)_{2} \\
& =(\mathrm{NPSH})_{n}-\left(\Delta h_{c}\right)_{n}=\text { const., }
\end{aligned}
$$

where the subscripts $1,2, \ldots n \ldots$ designate different fluids.

If the required fluid properties $\left(\lambda, v_{l}, v_{v}, T(p)\right.$, etc. $)$ are known, the prediction of the NPSH requirements for a given pump with any fluid by means of the results of this analysis requires the determination of two functions, $\Delta h_{p}$ and $\phi$ (or $\chi$ ). If both functions can be predicted theoretically no experimental work is required; this will probably not be the case.

A second relationship between NPSH and $\Delta h_{c}$ is presented here because it approximately predicts some NPSH's which have been measured with liquid hydrogen, liquid nitrogen and liquid oxygen; its use has not yet been justified on any other basis. Because (NPSH) should decrease as $\left(-\Delta h_{c}\right)$ increases, we assume that

Thus,

$$
(\mathrm{NPSH})\left(\Delta h_{c}\right)=a \text { constant. }
$$

$$
(\mathrm{NPSH})_{2}=(\mathrm{NPSH})_{1}\left\{\frac{\left(\Delta h_{c}\right)_{1}}{\left(\Delta h_{c}\right)_{2}}\right\} \text {. }
$$

The comments made above in connection with eqs (9 and 10), concerning the determination of the unknown functions, apply here also. Equations (7 or 8$)$ and either $(9,10,11$, or 12$)$ constitute pairs of relations which are examples of results of this analysis.

Due to the form of eq (7), the computation of the function $\phi$ from eq (10 or 12) involves the solution of a transcendental equation. In order to simplify computations an approximation to eq (7), based upon the assumption that

$$
\phi<\left|\left[1-\frac{C}{v_{l}}\left(\frac{d T}{d p}\right)\right]\right|
$$

will be derived. The error introduced by the assumption is not more than a few percent, the magnitude of the error depending upon the magnitude of the function $\phi$. Define:

$$
\delta \equiv \frac{\phi}{\left[1-\frac{C}{v_{l}}\left(\frac{d T}{d p}\right)\right]} .
$$

If $|\delta|<1$, we can write

$$
\Delta h_{c}=\frac{\lambda v_{l}}{v_{v}} \delta\left[1-\frac{1}{2} \delta+\frac{1}{3} \delta^{2}-\ldots \frac{1}{n+1} \delta^{n} \ldots\right] .
$$

The limitations of this restriction (i.e., $\delta<1$ ) must be determined through numerical computation. As there is no information available describing a fluid which deviates from stable equilibrium, stable equilibrium properties must be used in the computations; $\left(\frac{d T}{d p}\right)$ is then the slope of the vapor pressure curve, and the other properties are for saturated liquid and vapor. The data required for the computation and the results for three important cryogenic fluids at atmospheric pressure are given in table 1 . The computations show that the upper limit imposed upon the volume fraction of vapor in the cavitating region, $V$, to ensure the validity of eq (14) is very high. It is higher than any values for $V$ computed from the cryogenic data obtained by the author, and much higher than any values computed by Salemann 
[10]. This limit permits more than 99 percent of the cavitation region, with nitrogen or oxygen, to be filled with vapor, and more than 95 percent of the region to be filled with vapor in the case of hydrogen. Therefore this limitation on $V$ (or $\phi$ ) is probably unimportant.

Replacing eq (7) by eq (14) does not simplify computations because the transcendental function is merely replaced by its infinite series representation. A further development, which answers the following question, must be made: How many terms in eq (14) can be neglected without introducing unacceptable errors? The simplest computation results if only the first term is used. The maximum error introduced in the computed value of $\Delta h_{c}$ by neglecting all terms except the first is $(1 / 2) \delta$; this error is plotted as a function of $V$ in figure 2. Curves are shown for hydrogen, nitrogen, and oxygen at their normal boiling points, and for water at $70{ }^{\circ} \mathrm{F}$. The error with water is negligible, even when 95 percent of the cavitation region is filled with vapor. With nitrogen and oxygen the error is only 6 percent when 95 percent of the cavitation region is filled with vapor, and is less than 1 percent when there is less than 75 percent vapor. The largest error, with hydrogen, is less

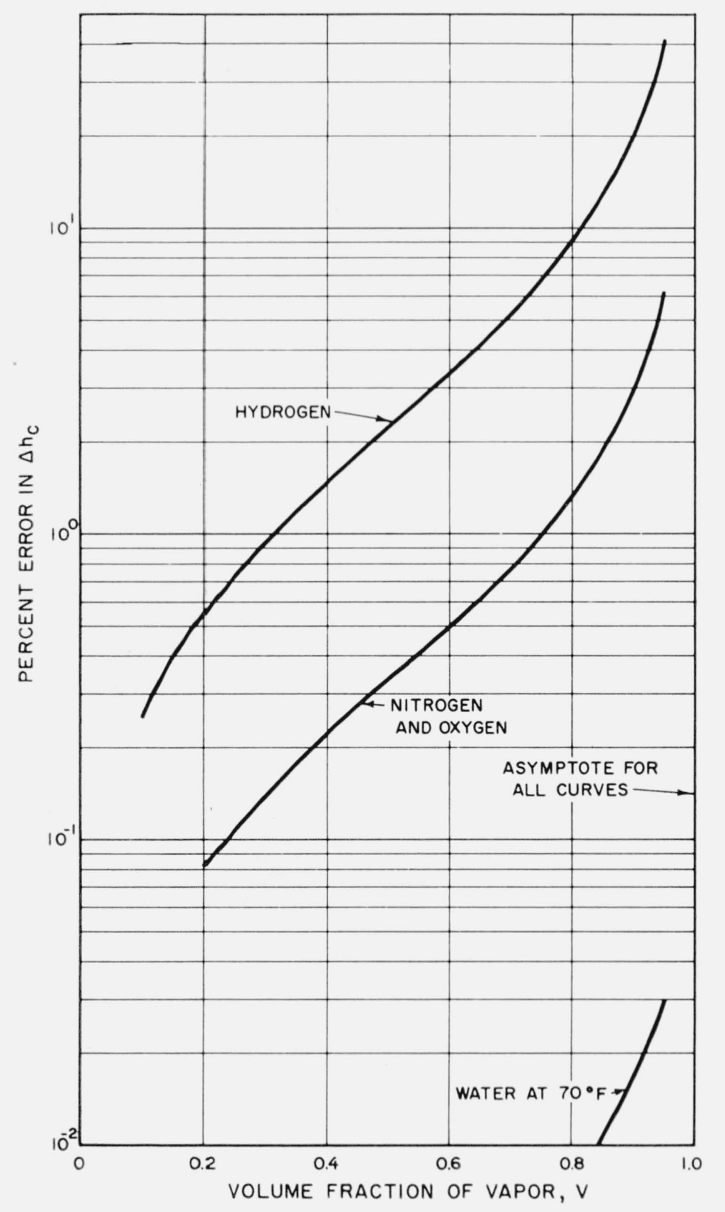

Figure 2. Percent error in $\Delta \mathrm{h}_{\mathrm{c}}$ due to use of only the first term in eq (14) versus the volume fraction of vapor (V) in the region of cavitation. than 10 percent when the volume of vapor is less than 82 percent. The values of $V$ computed from our data and those computed by Salemann [10] indicate that the use of only the first term in eq (14) will yield reasonably accurate values of $\Delta h_{c}$. Therefore $\Delta h_{c}$ will be computed from

$$
\Delta h_{c}=\frac{\lambda v_{l}}{v_{v}} \delta=\frac{\lambda v_{l}}{v_{v}} \frac{\phi}{\left[1-\frac{C}{v_{l}}\left(\frac{d T}{d p}\right)\right]} .
$$

Substitution of eq (15) in eqs (10 and 12) gives the simplified formulations for the prediction of NPSH:

$$
\begin{aligned}
(\mathrm{NPSH})_{2}=(\mathrm{NPSH})_{1} & +\left\{\frac{\lambda v_{l}}{v_{v}}\left[1-\frac{C}{v_{l}}\left(\frac{d T}{d p}\right)\right]\right\}_{2} \\
& -\left\{\frac{\lambda v_{l}}{v_{v}}\left[1-\frac{C}{v_{l}}\left(\frac{d T}{d p}\right)\right]\right\}_{1},
\end{aligned}
$$

and

$$
\begin{aligned}
(\mathrm{NPSH})_{2}=(\mathrm{NPSH})_{1} \frac{\left\{\frac{\lambda v_{l}}{v_{v}}\left[1-\frac{C}{v_{l}}\left(\frac{d T}{d p}\right)\right]\right\}_{1}}{\left\{\frac{\lambda v_{l}}{v_{v}}\left[1-\frac{C}{v_{l}}\left(\frac{d T}{d p}\right)\right]\right\}_{2}} .
\end{aligned}
$$

\begin{tabular}{|c|c|c|c|}
\hline Quantity & $\begin{array}{c}\text { Hydro- } \\
\text { gen }\end{array}$ & Nitrogen & Oxygen \\
\hline $\begin{array}{l}\text { Boiling point, }{ }^{\circ} \mathrm{K} \\
\text { Latent heat of vaporization, } \lambda, \text {, cal } / \mathrm{g} \\
\text { Isobaric specific heat, } C_{p}, \mathrm{cal} / \mathrm{g}{ }^{\circ} \mathrm{K} \\
\text { Specific volume of liquid, } v_{f}, \mathrm{~cm} 3 / \mathrm{g} \\
\text { Thermal expansion coefficient, } \beta_{f}, 1 /{ }^{\circ} \mathrm{K} \\
\text { Ratio of specific volume of saturated vapor to } \\
\text { that of saturated liquid, } v_{g} / v_{f}\end{array}$ & $\begin{array}{l}20.4 \\
106.5 \\
2.50 \\
14.11 \\
0.0175 \\
50\end{array}$ & $\begin{array}{l}77.32 \\
47.6 \\
0.489 \\
1.237 \\
0.00580 \\
183\end{array}$ & $\begin{array}{l}90.13 \\
50.8 \\
0.400 \\
.871 \\
.00738 \\
265\end{array}$ \\
\hline $\begin{array}{l}\text { Slope of vapor pressure curve }\left(\frac{d T}{d p}\right)_{v \cdot p} \text {. } \\
{ }^{\circ} \mathrm{K} \mathrm{cm}^{3} / \mathrm{cal}\end{array}$ & 132 & 383 & 336 \\
\hline Upper limit on $V$ for eq (14) to be valid.......... & 0.958 & 0.994 & 0.994 \\
\hline $\begin{array}{l}\text { Minimum NPSH required to suppress } \\
\text { symptoms of eavitation, ft.-- }\end{array}$ & 0.167 & 7.0 & $\begin{array}{l}10.6 \text { to } \\
15.7\end{array}$ \\
\hline
\end{tabular}

TABLE 1. Cryogenic fluid properties and data

Equation (16 or 17) would permit the prediction of the NPSH required to prevent symptoms of cavitation with fluid 2 if the NPSH requirements for fluid 1, the required fluid properties, the $\phi$-functions were known, and if the assumed relations between NPSH and $\Delta h_{c}$ (eqs 9 or 11) were valid. 
If it is further assumed that $\phi$ is not a function of the fluid properties, eqs (16 and 17) simplify to

$$
\begin{aligned}
(\mathrm{NPSH})_{2}=(\mathrm{NPSH})_{1}+\phi(N, Q) & \left\{\left[\frac{\lambda \frac{v_{l}}{v_{v}}}{1-\frac{C}{v_{l}}\left(\frac{d T}{d p}\right)}\right]_{2}\right. \\
& \left.-\left[\frac{\lambda \frac{v_{l}}{v_{v}}}{1-\frac{C}{v_{l}}\left(\frac{d T}{d p}\right)}\right]_{1}\right\}
\end{aligned}
$$

and

$$
(\mathrm{NPSH})_{2}=(\mathrm{NPSH})_{1} \frac{\left.\lambda \frac{\lambda \frac{v_{l}}{v_{v}}}{1-\frac{C}{v_{l}}\left(\frac{d T}{d p}\right)}\right]_{1}}{\left[\frac{\lambda \frac{v_{l}}{v_{v}}}{1-\frac{C}{v_{l}}\left(\frac{d T}{d p}\right)}\right]_{2}} \equiv(\mathrm{NPSH})_{1}\left(\frac{\tau_{2}}{\tau_{1}}\right) \text {, }
$$

respectively, where $\tau$ has been called the "cavitation tendency". The greater the cavitation tendency, the greater the required NPSH. The assumptions involved in the derivation of eqs (18 and 19) must be emphasized: the location of the cavitation region in a pump is independent of the fluid; the volume of vapor in this region, when cavitation symptoms arise, is independent of the fluid. The NPSH requirements which are to be compared are at the same operating points (i.e., the speed $(N)$ and flow $(Q)$ are the same for both fluids). In applying eq (18), the function, $\phi(N, Q)$ must be known, while application of eq (19) does not require a knowledge of the function.

\section{Experimental Comparison}

\subsection{Centrifugal Pumping}

In this section some experimental results which are pertinent to the analysis presented in the preceding section will be discussed. These indicate that the effects of the existence of metastable states, nucleation characteristics, and vapor-phase dynamics, are significant.

Only a meager amount of data is available to check the validity of eqs (18 and 19); some data have been reported by Salemann [10], and some have been obtained by the author. As no information is available concerning the deviation of the fluids from states of stable equilibrium during the tests, properties of saturated fluids are used in making comparisons.

One of the more drastic assumptions in the derivation of eq (18) is that $\phi$ is independent of the fluid being pumped. A straightforward way to check the equation is to substitute measured values of the minimum required NPSH and known values of fluid properties into the equation, and to determine if $\phi(N, Q)[=V /(1-V)]$ is constant. Salemann [10] did this for trichloromonofluoromethane, water, butane, and benzene, and found that $\phi$ varied from 0.25 to 1 .

In order to compare eq (19) with the data, we shall rewrite it as

$$
\frac{(\mathrm{NPSH})_{2}}{(\mathrm{NPSH})_{1}}=\frac{\tau_{2}}{\tau_{1}}=\left(\frac{\lambda_{1}}{\lambda_{2}}\right)\left(\frac{\left[\frac{v_{v}}{v_{l}}\right]_{2}}{\left[\frac{v_{v}}{v_{l}}\right]_{1}}\right)\left(\frac{\left[1-\frac{C}{v_{l}}\left(\frac{d T}{d p}\right)\right]_{2}}{\left[1-\frac{C}{v_{l}}\left(\frac{d T}{d p}\right)\right]_{1}}\right) .
$$

The validity of this expression can be checked by comparing the left-hand side (the experimental NPSH ratios) with the right-hand side (the theoretical cavitation-tendency ratios computed from fluid properties). The results of this comparison, using some of Salemann's data, are given in table 2. It is apparent that Salemann's data indicate that eqs (18 and 20) are not quantitatively valid, although the second equation may predict relative NPSH requirements for different fluids.

During the development of a hydrogen pumping system at this laboratory some crude NPSH data for hydrogen, nitrogen, and oxygen were obtained in a centrifugal pump designed for water. These data will be compared with eqs (18 and 20). Figure 3 is a schematic of the test apparatus used to obtain the data. 'The pump was a 10-stage submersible water pump rated at $3,450 \mathrm{rpm}, 9.7 \mathrm{gpm}$, and $100 \mathrm{ft}$ discharge head. The NPSH was determined by adding the liquid level above the pump suction,

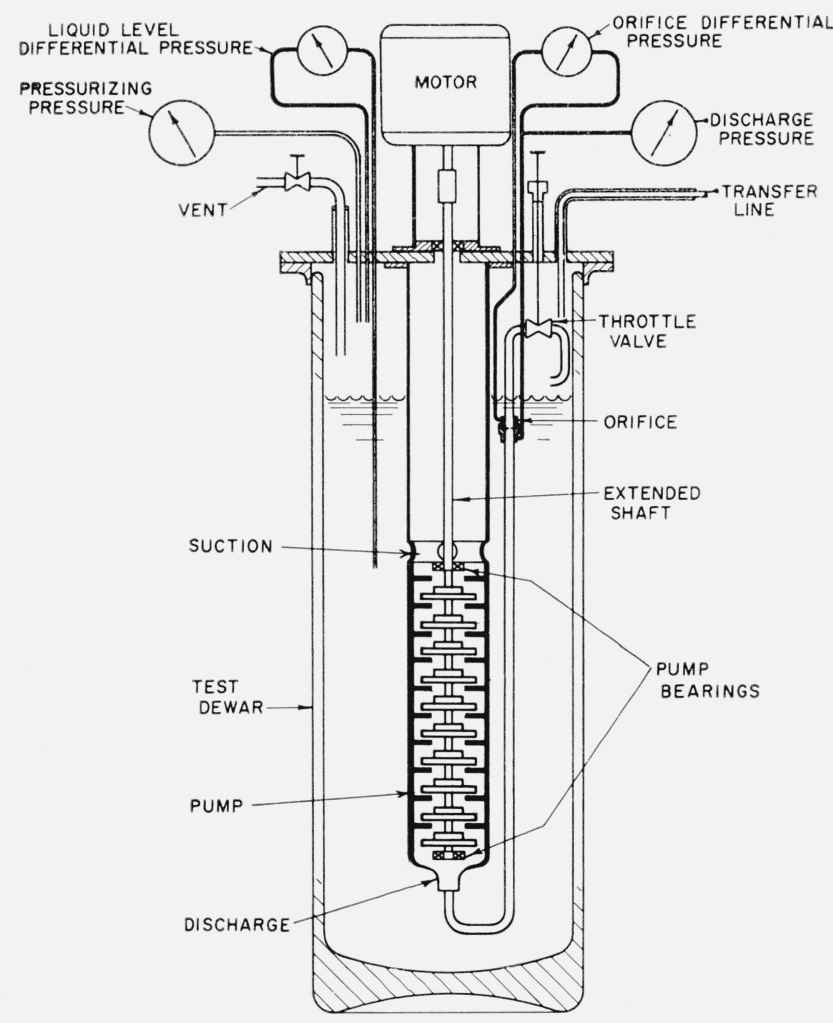

Figure 3. Pump test setup. 
measured with a hydrostatic device, to the pressure in the vapor space above the liquid. Readings were taken immediately after pressurization to minimize the rise in temperature of the fluid. The pressure in the vapor space was reduced to atmospheric between each set of readings so that the temperature would drop to the saturation temperature. (In a later apparatus the NPSH was determined by a vapor-pressure device [12] and the state of the fluid at the pump suction was controlled by a heat exchanger and a standpipe.) As the liquid in the test Dewar was very agitated, its temperature was assumed to be uniform at the saturation temperature corresponding to atmospheric pressure.

TABLE 2. Comparison of NPSH ratios to cavitation-tendency ratios for some of Salemann's [10] data

\begin{tabular}{|c|c|c|}
\hline Fluids & $\begin{array}{c}\text { Experi- } \\
\text { mental } \\
\text { (NPSH) } \\
\text { ratio }\end{array}$ & $\begin{array}{l}\text { Theoretical } \\
\text { cavitation } \\
\text { tendeney } \\
\text { ratios }\end{array}$ \\
\hline$\frac{\text { Freon }-11 \text { at } 85^{\circ} \mathrm{F}}{\text { Freon-11 at } 120^{\circ} \mathrm{F}}$ & 1. 21 & 2. 96 \\
\hline$\frac{\text { Water at } 2500^{\circ} \mathrm{F}}{\text { Water at } 300^{\circ} \mathrm{F}}$ & 1.28 & 4. 10 \\
\hline$\frac{\text { Water at } 2500^{\circ} \mathrm{F}}{\text { Freon-11 at }} \frac{120^{\circ} \mathrm{F}}{}$ & 1. 31 & 1. 80 \\
\hline
\end{tabular}

The minimum NPSH's required to suppress symptoms of cavitation were obtained by plotting suctionhead depression curves: for a given operating point the capacity and discharge head were plotted as functions of NPSH. Above the minimum required NPSH both the capacity and discharge head are independent of NPSH, while below this value both quantities decrease very rapidly (with decreasing NPSH). The breaks in both curves occurred at the same NPSH and were readily located on the graphs. The symptom of cavitation was taken to be the break in the curves; the minimum NPSH required to suppress symptoms of cavitation is defined as the NPSH adjacent to, and above, the breaks in the suction-head depression curves. (Figure 4 is included to indicate the type of data obtained.)

The measured values of minimum NPSH required to suppress symptoms of cavitation are given in table 1 . The low value for hydrogen has since been verified on other pumps by the author and by other investigators [13]. The minimum NPSH required for oxygen could only be bracketed between $10.6 \mathrm{ft}$ and $15.7 \mathrm{ft}$ because the tests were terminated when it was discovered that the liquid oxygen was eroding the pump.

Using data in table 1 , we can compute values of $\phi$ from eq (18), and then values of $V$ from the definition of $\phi$. Equation (18) satisfies our hydrogen and nitrogen data if the volume fraction of vapor, $V$, is 0.053 . It satisfies our nitrogen and oxygen data if the volume fraction of vapor is between 0.848 and 0.930 . Thus, these data lead to the same conclusion as the data of Salemann: that the formulation expressed by eq (18) (in which $\phi$ is assumed to be independent of the fluid being pumped) will not predict NPSH requirements.

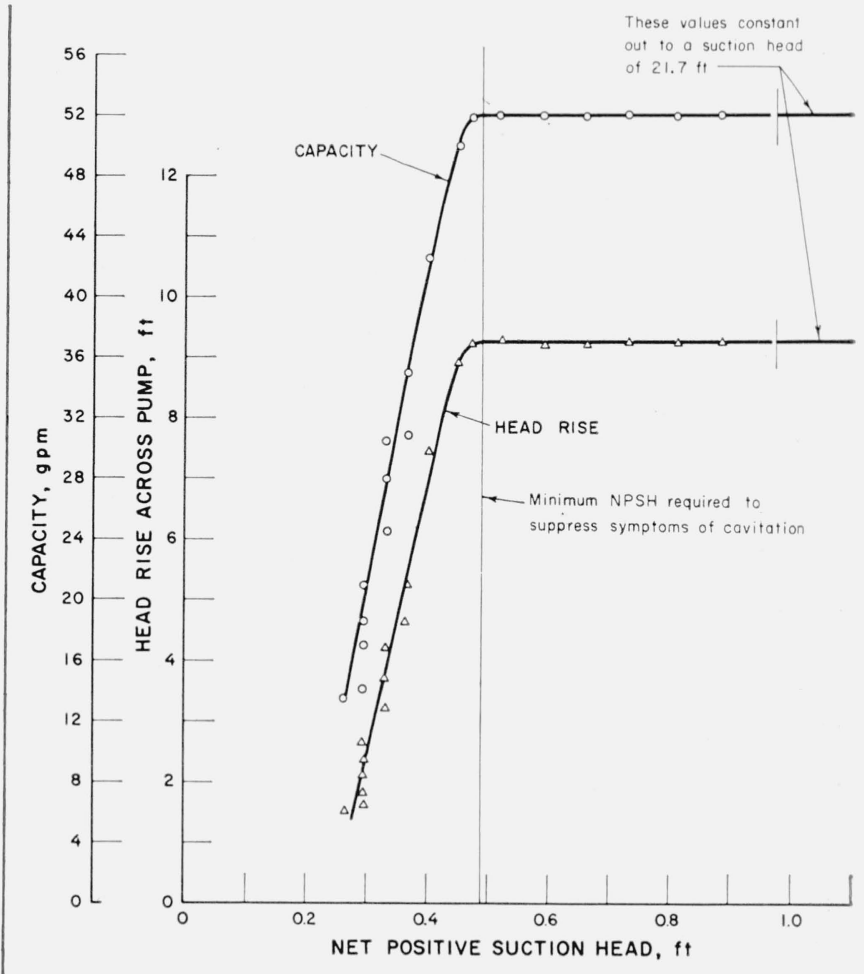

FIGURE 4. Suction head depression run for liquid hydrogen in a single-stage, submerged booster pump.

Speed: $5,450 \mathrm{rpm}$.

Rated flow.

The comparison between the cryogenic data and eq (20) is given in table 3 . The theoretical predictions are in qualitative agreement with the experimental results. It is not possible to say whether more refined experiments would produce better or worse agreement.

Thus, both Salemann's data and the cryogenic data indicate that eq (18) is invalid, while both sets of data indicate that eq (20) may have some value in predicting NPSH requirements. It should be pointed out that Salemann's experimental (NPSH) requirements were those which permitted a 3 percent drop in discharge head, not those required to prevent symptoms of cavitation entirely. The less satisfactory correlation of Salemann's data with eq (20) may be due, in part, to the possibility that a 3 percent decrease in performance appreciably affects the flow throughout the whole pump, and thus seriously violates assumptions made in the derivation of the equation. It should be noted that the assumptions that $\Delta h_{p}$ and $\phi$ are independent of fluid characteristics are very drastic, and may be responsible for the poor correlations presented above.

\subsection{Flow Measurement}

It has long been known (e.g., see Benjamin and Miller [14]) that even though a liquid passes through a region in which the static pressure falls below the vapor pressure, symptoms of cavitation need not occur. This means that even if the pressure at the 
vena contracta of an orifice or at the throat of a venturi is below the vapor pressure, such devices may still be accurate flow meters. As this situation exists in many applications it is desirable to be able to predict when cavitation will affect the performance of a flow meter.

TABLE 3. Comparison of NPSH ratios to cavitation tendency ratios for cryogenic liquids

\begin{tabular}{|c|c|c|}
\hline Fluids & $\begin{array}{l}\text { Experi- } \\
\text { mental } \\
\text { (NPSH) } \\
\text { ratio }\end{array}$ & $\begin{array}{l}\text { Theoretical } \\
\text { cavitation } \\
\text { tendency } \\
\text { ratios }\end{array}$ \\
\hline $\begin{array}{l}\text { Nitrogen: hydrogen } \\
\text { Oxygen: nitrogen } \\
\text { Oxygen: hydrogen }\end{array}$ & $\begin{array}{l}42 \\
1.51 \text { to } 2.24 \\
64 \text { to } 94\end{array}$ & $\begin{array}{l}55 \\
1.37 \\
75.5\end{array}$ \\
\hline
\end{tabular}

During an investigation to determine the behaviors of sharp-edged orifices with water, liquid nitrogen, and liquid hydrogen [7], it was not possible to produce cavitation symptoms as long as pure liquid entered the orifices. With liquid nitrogen, the pressures at the venae contractae were as much as 170 in. of liquid (4.9 psi) below the vapor pressure, while with liquid hydrogen the pressures at the venae contractae were as much as $192 \mathrm{in}$. of liquid (0.49 psi) below the vapor pressure. (These were the lowest pressures attainable with the apparatus.) The only way that symptoms of cavitation could be produced was to have two-phase flow entering the orifices; in many tests, even when two-phase flow entered the orifices, cavitation symptoms were not evident. Figure 5 is included here to show the results of some of the tests. Notice that only about one half of the nitrogen test points for which the upstream static pressure was below the vapor pressure show evidence of the presence of two-phase flow. Neither of the hydrogen points with upstream pressures below the vapor pressure appears to be affected by the twophase flow. It is also interesting that orifice calibration curves obtained with water may be quite satisfactory for use with liquid nitrogen and liquid hydrogen.
The absence of cavitation symptoms when the static pressure is below the vapor pressure is due to the fact that appreciable time is required to form a significant vapor phase and that the fluid elements are not in the low pressure region for the required length of time. The time depends upon the ability of the fluid to persist in metastable states, on nucleation characteristics, and on bubble dynamics including heat and mass transfer. Thus the same basic problems are involved here as with cavitation in pumps, and the analysis presented in section 2 may be applicable.

\subsection{Two-Phase Flow}

Except in the region where the vapor phase is initiated, two-phase single-component fluid flow is not normally associated with cavitation. However, as metastability is one of the basic phenomena associated with cavitation and as it has been observed that metastable states can exist throughout twophase, single-component fluid flows, some observations of these flows are presented here. The purpose in this section is to show that fluids can exist in metastable states for relatively long times; therefore, information of the types discussed in preceding sections would also be useful in this area.

The observations reported here were made in an apparatus designed to study steady, two-phase, single-component, fluid flow. This apparatus, described by Hatch [15], employs trichloromonofluoromethane. The curves in figure 6 show the existence of metastable states in the test section. The "measured temperature" curves were obtained from actual temperature measurements, while the "saturation temperature" curves were obtained from the saturation temperatures (taken from tables of thermodynamic data) corresponding to the measured pressures. It is obvious that the measured temperature lagged behind the saturation temperature, resulting in a superheated fluid. Here again, it can be concluded that vaporization does not occur rapidly enough to permit the attainment of stable equilibrium.

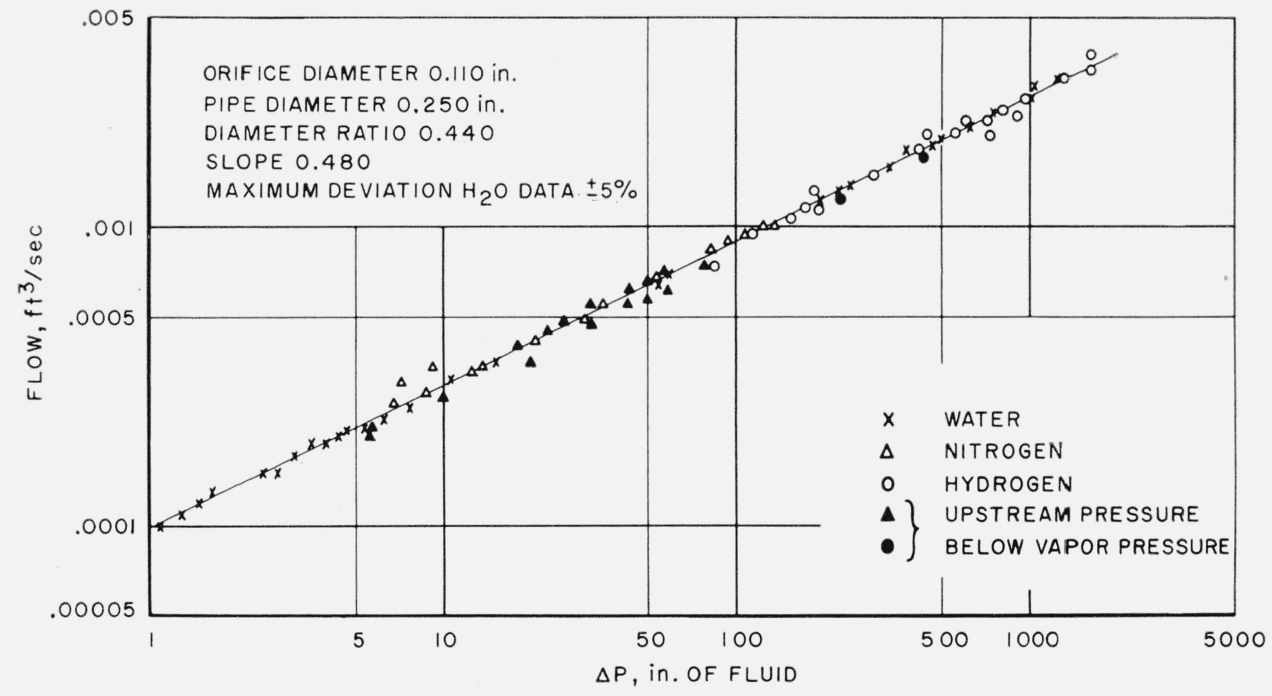

Figure 5. Calibration curve. 


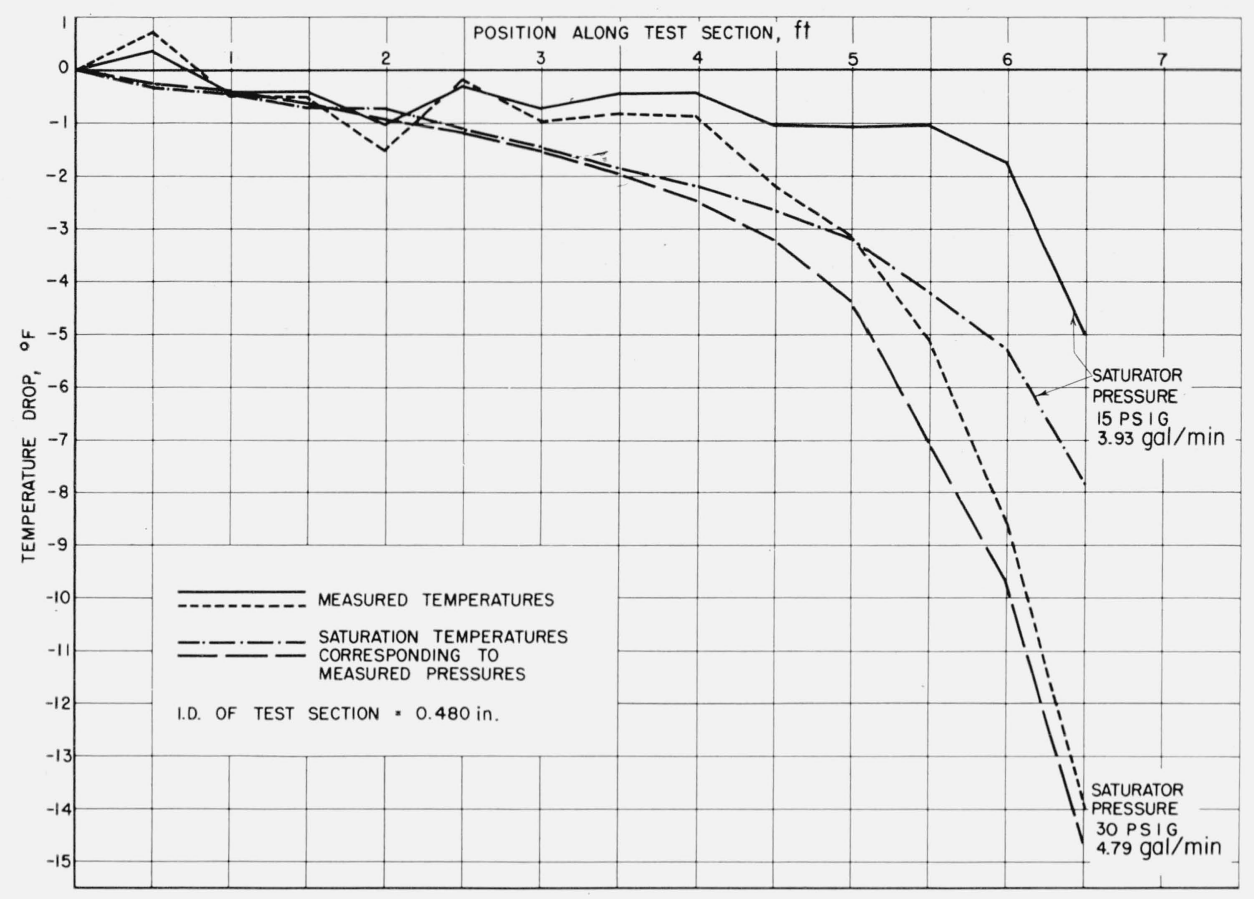

FiguRE 6. Two-phase flow data.

Measurements indicating differences between measured and saturation temperatures of more than $3{ }^{\circ} \mathrm{F}$ were common. If the two-phase pressure drops are computed from the Martinelli and Nelson [16] correlation, the existence of these metastable states can cause errors up to 15 percent. These observations stress once again the desirability of research into metastable equilibria. (It should be pointed out that the spatial oscillations of the measured temperatures in figure 6 are believed to actually occur; no fault could be found with the thermometry. They may be due to the nozzle at the inlet to the test section.)

\section{Conclusions}

Observations of hydraulic equipment in which cavitation occurs show that the existence of metastable equilibrium states, nucleation characteristics, and vapor-phase dynamies can be important in the prediction of cavitation characteristics. Investigations of fluid characteristics which influence such behavior are therefore necessary if cavitation symptoms are to be predicted.

The meager data available indicate that an approach of the type presented in section 2 may be fruitful in predicting symptoms of cavitation. In addition to the types of investigations suggested in the preceding paragraph, theoretical and experimental studies concerned with the determination of the $\phi$-function (or volume fraction of vapor in the cavitating region, $V$ ) should be continued. These studies should include work concerned with detailed pressure distribution within the equipment and the influence of the vapor region upon the detailed fluid mechanics of the equipment involved.
The qualitatively accurate predictions of the "Cavitation Tendency" concept suggest a desirability for further evaluation and refinement of this concept. However, the assumption that the $\phi$-function is not dependent upon fluid properties appears to be too drastic and eqs (16) and (17) should be used instead of eqs (18) and (19) whenever the $\phi$-function is known. As eq (16) was logically developed, while eq (17) was not, the former formulation is to be preferred; its poor correlation with available data may be due to the drastic assumption (i.e., $\phi$ independent of fluid) mentioned above. Finally it is suggested that, when sufficient information is available, eq (9) (and eqs (10) and (16)) should be modified to account for the delay in vapor formation which occurs between locations 1 and 2 in figure 1.

\section{References}

[1] E. E. Lindros, Actual NPSH requirements of centrifugal pumps compared to NPSH requirements as determined by laboratory tests, Presented at the ASME Cavitation Symposium, March 6-9, 1960, Rice Hotel, Houston, Texas.

[2] D. R. Rankin, Effect of varying available NPSH on the head-capacity curve of high specific speed pumps, Presented at the ASME Cavitation Symposium, March 6-9, 1960, Rice Hotel, Houston, Texas.

[3] W. W. Weltmer, The effects of air on the determination of critical NPSH, Presented at the ASME Cavitation Symposium, March 6-9, 1960, Rice Hotel, Houston, Texas.

[4] M. J. Hartmann and R. F. Soltes, Observation of the cavitation in a low hub-tip ratio axial flow pump, Paper No. 60-HYD-14, Presented at the ASME Cavitation Symposium, March 6-9, 1960, Rice Hotel, Houston, Texas. 
[5] G. M. Wood, J. S. Murphy, and J. Farquhar, An experimental study of cavitation in a mixed flow pump impeller, Paper No. 60-HYD-7, ASME Cavitation Symposium, March 6-9, 1960, Rice Hotel, Houston, Texas.

[6] H. A. Stahl and A. J. Stepanoff, Thermodynamic aspects of cavitation in centrifugal pumps, Trans. ASME 78, 1691 (1956).

[7] R. J. Richards, R. B. Jacobs, and W. G. Pestalozzi, Measurement of flow of liquefied gases with sharp-edged orifices, Adv. Cryogenic Eng. 4, 272-285 (Plenum Press, Inc., New York, N.Y., 1960).

[8] J. R. Purcell, A. F. Schmidt, R. B. Jacobs, The venturi tube as a liquefied gas flow measuring device, Adv. Cryogenic Eng. 5, 282-288 (Plenum Press, Inc., New York, N.Y., 1960).

[9] K. B. Martin, R. B. Jacobs, R. J. Hardy, Performance of pumps with liquefied gases, Adv. Cryogenic Eng. 2, 295-302 (Plenum Press, Inc., New York, N.Y., 1960).

[10] V. Salemann, Cavitation and NPSH requirements of various liquids, Trans. ASME, J. Basic Eng., p. 167 (June 1959).
[11] T. Y. Wu, The theory of cavitating flow, Presented at the Cavitation and Turbomachinery Conference, May 20, 1960, California Institute of Technology, Pasadena, Calif.

[12] R. B. Jacobs, K. B. Martin, and R. J. Hardy, Direct measurement of net positive suction head, Trans. ASME, J. Basic Eng., p. 147 (June 1959).

[13] G. H. Caine, L. J. Schafer, D. A. Burgeson, Pumping of liquid hydrogen, Adv. Cryogenic Eng. 4, 241-254 (Plenum Press, Inc., New York, N.Y., 1960).

[14] M. W. Benjamin and J. G. Miller, The flow of saturated water through throttling orifices, Trans. ASME 63, 419 (July 1941).

[15] M. R. Hatch, R. B. Jacobs, R. J. Richards, R. N. Boggs, G. R. Phelps, Prediction of pressure drop in twophase, single-component fluid flow, Adv. Cryogenic Eng. 4, 357-377 (Plenum Press, Inc., New York, N.Y., 1960).

[16] R. C. Martinelli and D. B. Nelson, Prediction of pressure drop during forced-circulation boiling of water, Trans. ASME 70, 695 (August 1948).

(Paper 65C3-65) 